\title{
A STABILITY RESULT FOR PARAMETER IDENTIFICATION PROBLEMS IN NONLINEAR PARABOLIC PROBLEMS
}

\section{STANISLAW MIGÓRSKI}

\author{
Institute for luformation Scicinces \\ Jagellomian University \\ ul. Nawojki 11, 30(07: Cracow \\ Poliuul \\ (Received March 15, 1993)
}

ABSTRACT. A sequence of identification problems of coefficients in the parabolic equation with nomlinear boundary conditions is consiclered. The parameter (index of an element of the sequence) appears in the cost functionals as well as boundary clata. It is proved that the optimal solutions exist and that under some continuous convergence of the cost functionals and the convergence of the data, the sets of optimal solutions converge in some sense to the set of optimal solutions of the limit problem:

IEY WORDS AND PHRASES. Inverse prollem, system iclentification, stalility of solutions, parabolic differential equation, nonlinear bomdary condition.

1992 AMS SUBJECT CLASSIFICATION. 35R3(), 35KG0.

\section{INTRODUCTION.}

In the recent years there has been an increasing interest in the paraneter identification (or inverse) problems involving differential equation constraints. Such problems arise in particular in the coefficient estimation for partial differential equations (for example in [2-3], [14], [17-18]) as well as in the theory of structural optimization. The identification problems consist in determining of unknown parameters (coefficients) from known olsservations of the modelled processes.

In this paper we investigate a class of identification problems for the second orcler nonlinear parabolic system:

$$
\begin{aligned}
& u^{\prime}=-\mathcal{A}(t) u \quad \text { in } \Omega \times(0, T), \\
& \frac{\partial u}{\partial{ }^{\prime} \mathcal{A}(t)}+\beta(u) \ni g \quad \text { in } \Gamma \times(0, T), \\
& u(0)=\varphi \quad \text { in } \Omega,
\end{aligned}
$$

where $\Omega \subset \mathbf{R}^{n}$ with boundary $\Gamma, 0<T<+\infty, \beta$ is a maximal monotone graph in $\mathbf{R} \times \mathbf{R}$, the operator $\mathcal{A}(t)$ has the form

$$
\mathcal{A}(t)=-\frac{\partial}{\partial x_{i}}\left(a_{i j}(x, t) \frac{\partial}{\partial x_{j}}\right)
$$

and

$$
\frac{\partial u}{\partial \nu_{\mathcal{A}}(t)}=a_{i j}(x, t) \frac{\partial u}{\partial x_{i}} \nu_{j}
$$

is the conormal derivative associated to $\mathcal{A}(t)$. Above, $\nu$ is the unit outward normal vector to $\Gamma$.

Given the set of adınissible parameters $\mathcal{M}$ and the cost functional $\mathcal{J}$ defined on the space 
$\mathcal{W}$ (see Notation) of the solutions to (1.1) - (1.3), we are interested in the following parameter iclentification problem:

$$
\left\{\begin{array}{l}
\text { find the parameters } a^{*}=\left\{a_{i j}^{*}(x, t)\right\} \text { in } \mathcal{M} \text { so that } \\
\mathcal{J}\left(u\left(a^{*}, g, \varphi\right)\right) \leq \mathcal{J}(u(a, g, \varphi)) \text { for all } a \in \mathcal{M},
\end{array}\right.
$$

where $u(a, g, \varphi)$ denotes the weak solution in $\mathcal{W}$ corresponding to the data a, $g$ and $\varphi$. Here and in what follows, we suppose that the graph $\beta$ is fixed.

Our aim is to prove the existence of optinal solutions (i.e. an clement which realizes the minimum) to $(\mathcal{P})$ and to show the stability of optimal solutions under perturbations of the data $\mathrm{g}$ and $\varphi$ as well as of the cost functional $\mathcal{J}$. As indicated in [1], [4-5] and [10-11] the stability of this kind plays an important role in applications.

It should be noticed that a compactuess of admissible subset of parameters is the crucial assumption in the identification problens (compare e.g. [5]). Since the cost functional is not convex in general, the uniqueness of optimal solutions is not guaranteed. Therefore the stability is unclerstood in the sense of continuity of multivalued mapping.

We note that the wiclely known approach to the parameter iclentification problems used also in numerical methods (see [4-5], [14]) is the output least squares formulation ([10-11], [13]). In this approach the cost functional to be minimized has the form

$$
\left\|\mathcal{C} u(a, g, \varphi)-z_{d}\right\|_{\mathbb{Z}}^{2}
$$

where $\mathcal{C}: \mathcal{W} \rightarrow \mathcal{Z}$ is an observation operator defined on the space of solutions, $z_{d}$ is the desired element (target) in the space of observations $\mathcal{Z}$. Such cases are also included in the frame of the paper. Next, it should be underlined that the iclontification of coefficients in partial differential equations is, in general, an unstible prolilem ([10-17], [13]). This is clue to the theory of homogenization $([8],[18])$ which shows that operators with higlhly oscillatory coefficients can be "replaced" by very different ones and still giving the same response.

Finally, we point out that the prollens of the type (1.1) - (1.3) occur in many mathematical models of phenomena studied in pliysics. For example, equation (1.1) describes the change of pressure cluring the flow of viscous fluids in porous media or it governs the heat distribution in a bocly occupying the volume $\Omega$. It is natural to consicler such problems not only with the classical (Dirichlet and/or Neumann) boundary conditions, but also with the more general ones. The boundary condition (1.2) includes some particular cases e.g. the Signorini conclition, the Stefan-Boltzmann heat radiation law, the Newton's law, the natural convection, the MichaelisMenten law. For these and other important examples of the condition (1.2) which appears in mechanics, biology and chemistry, we refor to [12], [7], [9] and the bibliography in them. We also recall that the evolution variational inequalities can be formulated in the form (1.1) - (1.3) (see [6], [9], [12], [15]). For the general identification theory presented in an abstract manner we refer to [13] and [1].

The remainder of this note is divided in three parts. In Section 2 we give a result on the continuous dependence of solution to boundary value problem (1.1) - (1.3) on the data. With this background, in Section 3, we show that the problem $(\mathcal{P})$ has a solution. The last section is devoted to the stability of optimal solutions with respect to variations in the given clata and the cost functional.

Notation. Let $\Omega$ be a bounded open subset of $\mathbf{R}^{n}$ with Lipschitz continuous boundary $\Gamma$. For a fixed real interval $[0, T]$, we introduce $Q=\Omega \times(0, T), \Sigma=\Gamma \times(0, T)$. Putting $V=H^{1}(\Omega)$, $H=L^{2}(\Omega)$, we denote by $\|\|,.|$.$| , the norms in V$ and $H$, respectively. By $V^{\prime}$ we denote the dual to $V$. Following e.g. [15], we define the Banach spaces: $\mathcal{V}=L^{2}(0, T ; V), \mathcal{H}=L^{2}(0, T ; H)$, $\mathcal{V}^{\prime}=L^{2}\left(0, T ; V^{\prime}\right)$ (the spaces of the square summable functions defined on $(0, T)$ with the values, 
resp., in $\left.V, H, V^{\prime}\right)$ and $\mathcal{W}=\left\{v \in \mathcal{V}: u^{\prime} \in \mathcal{V}^{\prime}\right\}$. H(re and subsequently the partial derivative with respect to $t$, is understood in the distributional sonse and $d v / d t$ will be denoted hy $v^{\prime}$. The pairing of $V$ and $V^{\prime}$ and also the inner product on $H$ is denoted by $<\cdot, \cdot>$. The symbol $<\cdot, \cdot>^{\prime}$ stands for the inner product on $L^{2}(\Gamma)$. Civen clesed sets $A$ and $B$ in a Banach space $X$, we define the distance function l,y $d(x, A)=i n f\left\{\|x-a\|_{x}: a \in A\right\}$ and the separation of a set $A$ from a siet $B$ l,y

$$
\iota^{*}(A, B)=s u p\{d(a, B): a \in A\}
$$

Throughout this paper a smumation convention over repeated sulscripts is adopted.

\section{CONTINUOUS DEPENDENCE ON THE DATA.}

The goal of this section is to study the question of continuous dependence of solutions to (1.1) - (1.3) on the clata $a_{i j}, g$ and $\varphi$. First we give the existence result on the solutions to this problem. To this end, we adopt the following

DEFINITION 2.1. (sce [7]) A function $u \in \mathcal{W}$ is a weak solution to (1.1) - (1.3) if and only if there exists a function $w \in L^{2}(\Sigma)$ such that

$$
w(\sigma, t) \in \beta(u(\sigma, t)) \text { a.c. on } \Sigma,
$$

and

$$
\begin{gathered}
<u^{\prime}(t), v>+a(t ; u(t), v)+<w(t), v>_{\mathrm{r}}=\left\langle g(t), v>_{\mathrm{r}} \quad \forall v \in V, \text { i.c. on }(0, T),\right. \\
u(0)=\varphi,
\end{gathered}
$$

wliere we have set

$$
a(t ; z, v)=\int_{\Omega} a_{i j}(x, t) \frac{\partial z}{\partial x_{i}} \frac{\partial v}{\partial x_{j}} d x, \quad \forall z, v \in V \text {, a.e. } t \in(0, T) .
$$

We need the following hypotheses on the datia of the problem (1.1) - (1.3):

$\left(H_{1}\right)$ the coefficients $\left\{a_{i j}\right\}, i, j=1, \ldots, n$ are functions from $C(\bar{Q})$ such that

$$
\alpha \xi_{i} \xi_{i} \leq a_{i j}(x, t) \xi_{i} \xi_{j}, \quad \forall \xi \in \mathbf{R}^{n}
$$

a.e. in $Q$, for some constant $\alpha>0$,

$\left(H_{2}\right) \quad \beta$ is a maximal (multivalued) monotone graph in $\mathbf{R} \times \mathbf{R}$ which satisfies the condition $0 \in \beta(0)$,

$\left(H_{3}\right) \quad g \in L^{2}(\Sigma), \varphi \in H$.

It is well known (see e.g. [0]) that $\beta$ is a subdifferential of a proper, convex, l.s.c. function $j: \mathbf{R} \rightarrow \mathbf{R} \cup\{+\infty\}$, i.e. $\beta=\partial j$.

PROPOSITION 2.1. In addition to the liypotheses $\left(H_{1}\right)-\left(H_{3}\right)$ we assume that $j(\varphi) \in$ $L^{1}(\Omega)$. Then the problem (1.1) - (1.3) has a unique weak solution $u \in \mathcal{W}$. Morover, the following estimate holds:

$$
\|u\|_{W}+\|w\|_{L^{2}(\Sigma)} \leq c\left(1+\|g\|_{L^{2}(\Sigma)}+|\varphi|\right),
$$

where $w \in L^{2}(\Sigma)$ is a selection of $\beta$ which appears in (2.1) and $c \in \mathbf{R}$ is independent of $g$ and $\varphi$.

The proof of this result can be found in [7], Proposition 1, where the overall hypotheses on the coefficients $a_{i j}$ were more restrictive. A careful look in that proof can convince the reader that it is still true for the case of coefficients satisfying $\left(H_{1}\right)$.

Let $\left\{a_{i j}^{k}\right\}, k \in \mathrm{N}$, be a secquence in $C(\bar{Q})$ satisfying (2.3) uniformly with respect to $k$ and let $\left\{\left(g_{k}, \varphi_{k}\right)\right\}$ be a sequence in $L^{2}(\Sigma) \times H$. Denoting by $u_{k}=u\left(a_{i j}^{k}, g_{k}, \varphi_{k}\right)$ the solution to (1.1) (1.3) corresponding to $\left\{a_{i j}^{k}\right\},\left\{\left(g_{k}, \varphi_{k}\right)\right\}$, we have

LEMMA 2.1. Under the above notations, let us assume that $\beta$ satisfies $\left(H_{2}\right)$ and $j\left(\varphi_{k}\right) \in$ $L^{1}(\Omega)$. If

$$
a_{i j}^{k} \rightarrow a_{i j} \text { in } C(\bar{Q}), \quad \forall i, j
$$




$$
\left(g_{k}, \varphi_{k}\right) \rightarrow(g, \varphi) \text { in } \quad L^{2}(\Sigma) \times H
$$

as $k \rightarrow+\infty$, then

$$
u_{k} \rightarrow u \text { in } \mathcal{V} \cap C^{\prime}\left(0, T^{\prime} ; H\right) \text { and weakly in } \mathcal{W},
$$

as $k \rightarrow+\infty$, where $u=u\left(u_{i j}, g, \varphi\right)$ is a uniqun solution (still in the sense of Definition 2.1) to) $(1.1)$ - (1.3) correspondling to $a_{i, j}, g$ ind $p$.

PROOF. Note that by lower semicontinuty of $j$, it follows that $j(\varphi) \in L^{1}(\Omega)$. Therefore, from Proposition 2.1, we know that there exists a mique solution to (1.1) - (1.3) corresponding to $a_{i j}, g$ and $\varphi$. Substracting two equations which are satisfied by $u_{k}$ and $u$, we obtain

$$
\begin{gathered}
<u_{k}^{\prime}(s)-u^{\prime}(s), u>+u_{k}\left(s ; u_{k}(s), v\right)-a(s ; u(s), v)+ \\
\quad+<u_{k}(s)-u(s), v>_{r}=<g g_{k}(s)-g(s), v>\Gamma
\end{gathered}
$$

for all $v \in V$, a.e. $s \in(0, T)$, where $w, w_{k} \in L^{2}(\Sigma)$ are such that

$$
u(\sigma, s) \in \beta(u(\sigma, s)), \quad w_{k}(\sigma, s) \in \beta\left(u_{k}(\sigma, s)\right) \text { a.e. on } \Sigma
$$

and $a(\cdot ; \cdot, \cdot), a_{k}(\cdot ; \cdot, \cdot)$ are of the form $(2.2)$ with the coefficients $a_{i j}, a_{i j}^{k}$, respectively.

Taking $u_{k}(s)-u(s)$ as the function $v$ und integrating both sides we get:

$$
\begin{gathered}
\frac{1}{2}\left|u_{k}(t)-u(t)\right|^{2}+\int_{0}^{t} a_{k}\left(s ; u_{k}(s)-u(s), u_{k}(s)-u(s)\right) d s+ \\
+\int_{0}^{t}<w_{k}(s)-w(s), u_{k}(s)-u(s)>_{1} d s=\frac{1}{2}\left|\varphi_{k}-\varphi\right|^{2}+\int_{0}^{t}\left(a\left(s ; u(s), u_{k}(s)-u(s)\right)-\right. \\
\left.-a_{k}\left(s ; u(s), u_{k}(s)-u(s)\right)\right) d s+\int_{0}^{t}<g_{k}(s)-g(s), u_{k}(s)-u(s)>_{\Gamma} d s .
\end{gathered}
$$

Hence, from $\left(H_{1}\right)$ and $\left(H_{2}\right)$ we olstain:

$$
\begin{aligned}
& \left|u_{k}(t)-u(t)\right|^{2}+2 \alpha \int_{0}^{l}\left\|u_{k}(s)-u(s)\right\|^{2} d s \leq\left|\varphi_{k}-\varphi\right|^{2}+ \\
& +\int_{0}^{t} \sum_{j=1}^{n}\left|\sum_{i=1}^{n}\left(a_{i j}^{k}-a_{i j}\right) \frac{\partial u(s)}{\partial x_{i}} \| \frac{\partial u_{k}(s)}{\partial x_{j}}-\frac{\partial u(s)}{\partial x_{j}}\right| d s+ \\
& +2 \int_{0}^{l}\left|g k_{k}(s)-g(s)\right|_{L^{2}(\Gamma)}\left|u_{k}(s)-u(s)\right|_{L^{2}(\Gamma)} d s .
\end{aligned}
$$

Using the continuity of the trace operator from $V$ to $L^{2}(\Gamma)$ and the inequality $2 a b \leq \frac{2}{\alpha} a^{2}+$ $\frac{\alpha}{2} b^{2}$, we have

$$
\begin{gathered}
\left|u_{k}(t)-u(t)\right|^{2}+\alpha \int_{0}^{t}\left\|u_{k}(s)-u(s)\right\|^{2} d s \leq\left|\varphi_{k}-\varphi\right|^{2}+ \\
+c_{1}\|u\|_{\mathcal{V}}^{2} \sum_{i, j=1}^{n}\left\|a_{i j}^{k}-a_{i j}\right\|_{C^{\prime}(\bar{\delta})}+c_{2} \int_{0}^{t}\left|g_{k}(s)-g(s)\right|_{L^{2}(\Gamma)} d s,
\end{gathered}
$$

where $c_{i}, i=1,2$ are positive constants inclependent of $k$. From this, (2.4) and from the hypotheses we deduce that

$$
u_{k} \rightarrow u \text { in } \mathcal{V} \cap C^{\prime}(0, T ; H) \text {, as } k \rightarrow+\infty \text {. }
$$

On the other hand, owing to the estimate (2.4), which is uniform with respect to $k$, we obtain

$$
u_{k} \rightarrow u \text { weakly in } \mathcal{W} \text {, as } k \rightarrow+\infty \text {. }
$$

The uniqueness of solutions of problem (1.1) - (1.3) implies that the whole sequence $\left\{u_{k}\right\}$ converges to $u$ in the sense of (2.5). This completes the proof of the lemna. 


\section{EXISTENCE RESULT IN IDENTIFI(ATION.}

Using the result of Lemnna 2.1 , we ain prove the existence of solution of the identification problem ( $P$ ). This is given in the following

THEOREM 3.1. Let the assunptions of Propesition 2.1 hold. We suppese that the set of achinissille paraneters satisfics

$\left(H_{1}\right) \quad$ the set $\mathcal{M}$ is a compract sulsset of $\left(C^{\prime}(\bar{Q})\right)^{n^{2}}$ such that $\alpha \xi_{i} \xi_{i} \leq a_{i j}(x, t) \xi_{i} \xi_{j}$ for each $\xi \in \mathbf{R}^{\prime \prime}$ and for all $a=\left\{a_{i j}(x, t)\right\}$ in $\mathcal{M}$.

Let the cost functional $\mathcal{J}: \mathcal{W} \rightarrow \mathbf{R}$ be weakly secquentially lower senicontinuons on $\mathcal{W}$. Then the problem ( $P$ ) has a solution.

PROOF. We apply the direct method of calculus of variations (see e.g. [1]). Let $g, \varphi$ satisfy $\left(H_{3}\right)$ and let $\left\{a_{k}\right\}$ be a minimizing secpuence fiom $\mathcal{M}$ such that

$$
\lim _{k \rightarrow \infty} \mathcal{T}\left(u\left(a_{k}, g, \varphi\right)\right)=\operatorname{iuf}\{\mathcal{T}(u(u, g, \varphi)): a \in \mathcal{M}\}=m .
$$

Since $\mathcal{M}$ is compact, there exists a sulsecquence of the secquence $\left\{a_{k}\right\}$, relabeled again as $\left\{a_{k}\right\}$, and a $a_{0} \in \mathcal{M}$ such that $a_{k} \rightarrow a_{0}$. It follows from Lemma 2.1 that in particular

$$
u\left(a_{k}, y, \varphi\right) \rightarrow u\left(a_{0}, y, \varphi\right) \text { weakly in } \mathcal{W} \text {, as } k \rightarrow+\infty .
$$

Therefore, by lower semicontinuity of 7 we have

$$
m \leq \mathcal{J}\left(u\left(a_{0}, g, \varphi\right)\right) \leq \liminf _{k \rightarrow \infty} \mathcal{T}\left(u\left(a_{k}, g, \varphi\right)\right)=\lim _{k \rightarrow \infty} \mathcal{J}\left(u\left(a_{k}, g, \varphi\right)\right)=n .
$$

Heilec the result follows.

REMARK 3.1. In general, without convexity assumptions, we do not expect uniqueness of the optimal solution in iclentification ([1], [16]).

\section{STABILITY RESULT.}

In this section we give the nain result of this paper on the depenclence (hence also the stability) of the optimal elements for the problem $(\mathcal{P})$ on the data as well as on the cost functional.

We consider the sequence (inclexed by the parameter $k \in \mathrm{N}$ ) of the identification problems:

$$
\left(\mathcal{P}_{k}\right)\left\{\begin{array}{l}
\text { find } a^{*}=\left\{a_{i j}^{*}\right\} \text { in } \mathcal{M} \text { so that } \\
\mathcal{J}_{k}\left(u\left(a^{*}, g_{k}, \varphi_{k}\right)\right) \leq \mathcal{J}_{k}\left(u\left(a, g_{k}, \varphi_{k}\right)\right) \text { for all } a \in \mathcal{M},
\end{array}\right.
$$

where $u\left(a, g_{k}, \varphi_{k}\right)$ are the solutions in $\mathcal{W}$ to $(1.1)$ - (1.3) corresponding to the perturbed data $g_{k}, \varphi_{k}$ and $\mathcal{J}_{k}$ are the perturbed functionals. We show that the set of optimal solutions to $\left(\mathcal{P}_{k}\right)$ converges in some sense, to the set of optimal solution to $(\mathcal{P})$.

We need the following continuons convergence of functionals. Let $(\mathcal{X}, \tau)$ be a topological space and $\mathcal{J}_{k}: \mathcal{X} \rightarrow \mathbf{R}$.

DEFINITION 4.1. We say that a secpuence of functionals $\left\{\mathcal{J}_{k}\right\}, k \in \mathrm{N}$, is sequential continuously convergent (shortly, $C_{s e q}$-converges) to $\mathcal{J}$, and we write $\mathcal{J}=C_{s e q}(\tau-\mathcal{X}) \lim _{k \rightarrow \infty} \mathcal{J}_{k}$, if for every $x \in \mathcal{X}$ and for every $\left\{x_{k}\right\} \subset \mathcal{X}$ which $\tau$-converges to $x$, the sequence $\mathcal{J}_{k}\left(x_{k}\right)$ converges to $\mathcal{T}(x)$.

For each $k \in \mathrm{N}$, we denote by $\mathcal{S}, \mathcal{S}_{k}$ the sets of optimal elements to the problem $(\mathcal{P}),\left(\mathcal{P}_{k}\right)$, respectively, i.e.

$$
\begin{gathered}
\mathcal{S}=\mathcal{S}(g, \varphi, \mathcal{J})=\left\{a^{*} \in \mathcal{M}: \mathcal{J}\left(u\left(a^{*}, g, \varphi\right)\right) \leq \mathcal{J}(u(a, g, \varphi)), \quad \forall a \in \mathcal{M}\right\}, \\
\mathcal{S}_{k}=\mathcal{S}\left(g_{k}, \varphi_{k}, \mathcal{J}_{k}\right)=\left\{a^{*} \in \mathcal{M}: \mathcal{J}_{k}\left(u\left(a^{*}, g_{k}, \varphi_{k}\right)\right) \leq \mathcal{J}_{k}\left(u\left(a, g_{k}, \varphi_{k}\right)\right), \quad \forall a \in \mathcal{M}\right\} .
\end{gathered}
$$

With the above notation we have 
THEOREM 4.1. In addition to the hypotheses $\left(H_{2}\right)$ and $\left(H_{4}\right)$, we assiune that $\mathcal{J}, \mathcal{J}_{k}: \mathcal{W} \rightarrow$ $\mathbf{R}$ are given weakly secfucutially lower senuicontinumus functionals. Let $g, g k \in L^{2}(\Sigma)$ and $\varphi_{,} \varphi_{k} \in$ $H$ be such that $j\left(\varphi_{k}\right) \in L^{1}(\Omega)$. If

$$
\begin{gathered}
\left\{\left(y_{k}, \varphi_{k}\right)\right\} \rightarrow(y, \varphi) \text { in } L^{2}(\Sigma) \times H, \text { ais } \quad k \rightarrow+\infty, \\
\mathcal{T}=C_{\text {scy }}(11-\mathcal{W}) \lim _{k \rightarrow \infty} J_{k},
\end{gathered}
$$

(where $w-\mathcal{W}$ stands for the weak topology in $\mathcal{W}$ ), then

$$
\lim _{h \rightarrow \infty} l^{*}\left(\mathcal{S}_{k}, \mathcal{S}\right)=0
$$

where $h^{*}(\cdot, \cdot)$ is defined in (1.5).

PROOF. We argue hy contradiction. If (4.3) is not verified there exist $\bar{\varepsilon}>0$ and a sequence $\left\{k_{\nu}\right\}, k_{\nu} \rightarrow+\infty$ such that

$$
\bar{\varepsilon}<l^{*}\left(\mathcal{S}_{k_{\nu}}, \mathcal{S}\right), \forall k_{\nu} \in \mathrm{N} .
$$

Clearly, there exist $a_{k_{\nu}}^{*} \in \mathcal{S}_{k_{\text {, }}}$ such that

$$
\bar{\varepsilon}<l\left(a_{k_{\nu}}^{*}, \mathcal{S}\right), \forall k_{\nu} \in \mathrm{N} .
$$

In riew of compactuess of $\mathcal{M}$, we deduce that there exists a subsecuence of $\left\{a_{k_{\nu}}^{*}\right\}$, that we will denote in the sanne way, such that

$$
a_{k_{\nu}}^{*} \rightarrow a^{*} \text { in }(C(\bar{Q}))^{u^{2}} \text {, as } k_{\nu} \rightarrow+\infty
$$

for some $a^{*} \in \mathcal{M}$.

Let now $u_{k_{\nu}}^{*}=u\left(a_{k_{\nu}}^{*}, g k_{\nu}, \varphi_{k_{\nu}}\right)$ and $u^{*}=u\left(a^{*}, y, \varphi\right)$ denote the solutions to (1.1) - (1.3) which correspond to the triples $\left(a_{k_{v}}^{*}, g k_{k_{r}}, \varphi_{k_{v}}\right)$ and $\left(a^{*}, g, \varphi\right)$, respectively. From (4.1) and (4.5) Lemmir 2.1 gives

$$
u_{k_{\nu}}^{*} \rightarrow u^{*} \text { weakly in } \mathcal{W} \text {, as } k_{\nu} \rightarrow+\infty
$$

Since the functionals $\mathcal{T}_{k} C_{\text {se: }}$-converges to $\mathcal{T}$, we get

$$
\mathcal{J}\left(u^{*}\right)=\lim \mathcal{J}_{k_{\nu}}\left(u_{k_{\nu}}^{*}\right)
$$

Let us fix an arbitrary $a \in \mathcal{M}$. Let $u_{k_{v}}=u\left(a, g k_{v}, \varphi_{k_{v}}\right)$ and $u=u(a, g, \varphi)$ be the solutions to (1.1) - (1.3) with the indicated data. From the continuous dependence on the data, we conclude that

$$
u_{k_{\nu}} \rightarrow u \text { weakly in } \mathcal{W} \text {, as } k_{\nu} \rightarrow+\infty
$$

Hence, as above, we have

$$
\mathcal{J}(u)=\lim \mathcal{J}_{k_{v}}\left(u_{k_{u}}\right)
$$

Since $a_{k_{\nu}}^{*}$ are in $\mathcal{S}_{k_{\nu}}$, we have

$$
\mathcal{T}_{k_{\nu}}\left(u_{k_{\nu}}^{*}\right) \leq \mathcal{J}_{k_{\nu}}\left(u_{k_{\nu}}\right)
$$

In the limit, as $k_{\nu} \rightarrow+\infty$, one gets from (4.6), (4.7) :

$$
\mathcal{J}\left(u\left(a^{*}, g, \varphi\right)\right) \leq \mathcal{J}(u(a, g, \varphi)), \quad \forall a \in \mathcal{M} .
$$

From the arbitrariety of $a \in \mathcal{M}$, we have $a^{*} \in \mathcal{S}$ and this implies that

$$
d\left(a_{k_{\nu}}^{*}, \mathcal{S}\right) \leq\left\|a_{k_{\nu}}^{*}-a^{*}\right\| .
$$

But now from (4.5), we olstain that (4.8) contradicts (4.4). This proves (4.3) and completes the proof of the theorem. 
The convergenere (4.2) holels, for instance, for the sepuence of functionals of the form (1.4). Nantely, the following two cases can le considered:

(i) Let $\mathcal{Z}=\mathcal{H}$. Given the finctionals $\mathcal{T}_{k}(u)=\left\|u-z_{d}^{k}\right\|_{\mathcal{H}}^{2}$, where $\left\{z_{d}^{k}\right\}$ is a secpuence of pertumbed distributed observations in $\mathcal{H}$ converging to $z_{d}$, we have that (4.2) is satisfied with $\mathcal{T}(u)=\left\|u-z_{d}\right\|_{\mathfrak{H}}^{2}$. This follows directly, l,y the dedinition of $C_{\text {*aq }}$-linint, from the faret that $\mathcal{W} \subset \mathcal{H}$ and this embeding is compact (companc [15]).

(ii) Let $\mathcal{Z}=L^{2}(\Sigma)$. We consider the functionals $\mathcal{J}_{k}(u)=\left\|u-z_{d}^{k}\right\|_{L^{2}(\Sigma)}^{2}$, where $\left\{z_{d}^{k}\right\}$ is a sequence of pertubed measurements (observations) performed on $\Sigma$. If $z_{d}^{k} \rightarrow z_{d}$ in $L^{2}(\Sigma)$, as $k \rightarrow+\infty$, then using the compartuess of the trace cunledeling fiom $\mathcal{W}$ into $L^{2}(\Sigma)$, we easily get the convergence (4.2), where $J(u)=\left\|u-z_{d}\right\|_{l^{2}(\Sigma)}^{2}$.

REMARK 4.1. O)e can generalize the results presented above to the case when $\mathcal{A}(t)$ is a differential operator of the form

$$
\mathcal{A}(t)=-\frac{\partial}{\partial x_{i}}\left(a_{i j}(x, t) \frac{\partial}{\partial x_{j}}\right)+a(x, t) u .
$$

()ur theory, with some ninor changes, can handle inverse problems involving the iclentification of any of the parameters $a_{\imath, j}, a$, or initial clata or boumclary function.

REMARK 4.2. A futher generalization of our results can be obtained considering the identification problems for (1.1) - (1.3) with the mixed lomudary conditions

$$
\frac{\partial u}{\partial \nu_{\mu}(t)}+\beta_{i}(u) \ni y_{i} \text { on } \Sigma_{i}, \quad i=1,2
$$

instead of (1.2), where $\Sigma_{i}=\Gamma_{i} \times(0, T)$ and $\Gamma_{i}$ are the disjoint parts of $\Gamma$. The exact formulation of the results with obvious modifications is left to the interested reader.

ACKNOWLEDGEMEN'T. The pipere was write'n while the anthor was visiting the Scuola Normale Superiore di Pisa and was supported by the Istituto Nazionale di Alta Matematica Francesco Severi, Rome, Italy. This work was partially funded by a National Research Project in Mathematics "Equazioni Differenziali e Calcolo clelle Variazioni" of the Ministero dell'Universitá e della Ricerca Scientifica e Tecuologia, $40 \%$ contracts.

\section{REFERENCES}

1. AHMED,N.U. Optimization and Irlentification of Systems Governed by Evolution Equations on Banach Space, Pitman Rescanch Notes in Mathematics 184 , Longman, Boston London - Melboune, 1988.

2. BALAKRISHNAN, A.V. Iclentification of distributed parameter systems: non-computational aspects, Proceedings IFIP Working Conference, Rome, 1976, A.Ruberti, Ed., Lecture Notes in Control and Information Sciences, Vol.1, Springer-Verlag, Berlin, 1978, 1-10.

3. BAMBERGER, A., CHAVENT, G. and LAILLY, P. About the stability of the inverse problem in 1-D wave equations - applications to the interpretation of seismic profiles, Appl. Mat.h. Optin. $\underline{5}$ (1979), 1-47.

4. BANKS, H.T. On a variational approach to some parameter estimation problems, ICASE Rep. No. 85-32. NASA Langley Res. C.tr., Hanntom, VA, Jume, 1985.

5. BANKS, H.T. and ILES, D.W. On compactness of admissible parameter sets, Proceedings IFIP Working Conference, Gainsville, 1986, I.Lasiecka, R. Triggiani Eds., Lecture Notes in Control and Information Sciences, Vol.97, Springer-Verlag, Berlin, 1987, 130142. 


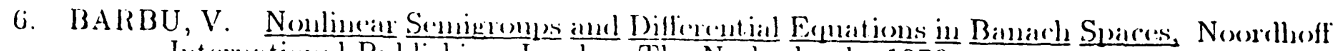

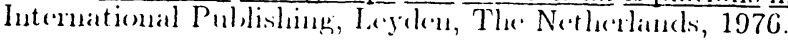

7. BARBU, V. Bonulany control pollenens with nonlinear state ecpuation, SIAM J. Control $\underline{O_{1}+\mathrm{ini}} . \underline{20}(1082), 125-143$

8. BENSOUSSAN, A., LIONS, J.L. anl PAPANIC(OLAOU, G. Asymptotic Analysis for

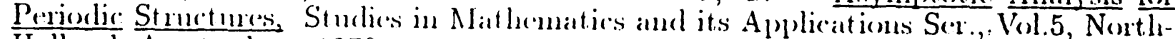
Holland, Anstordiun, 1978.

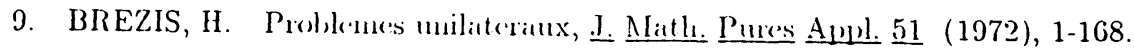

10. COLONIUS, F. and KUNISCII, K. Output least syuares stability for estimation of the diffusion coefficient in an colliptic expation, Procerdings IFIP Working Conference, Gainsville, 1986, I.Lasicelia, R.Triggiani Eds., Lecture Notes in Control and Informat tion Sricuces, Vol.97, Springer-Verlag, Berlin, 1987, 185-195.

11. COLONIUS, F. and KUNISCH, K. Stability for Parameter Estimation in Two Point

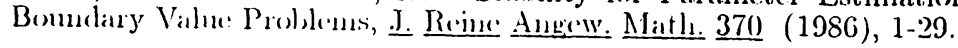

12. DUVAUT, G. and LIONS, J.L. I..s Incunitions on Macanicule et en Pliysique, Dunod, Paris, 1972.

13. KRAVARIS, C. and SEINFELD, J.II. Identification of parameters in distributed paraneter systems by regularization, SIAM J. Comitrol (O)tine. 23 (1085), 217-241.

14. KUNISCH, K. Identification and Estimation of Paraneters in Alstract Cauchy Problems,

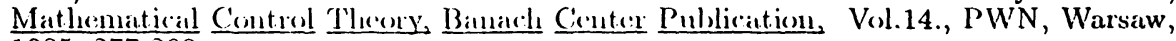
$1985,277-298$.

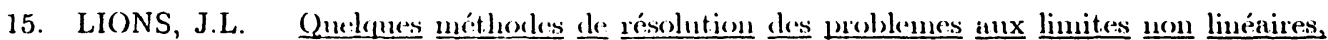
Dunod-Ganthicr Villiars, Paris, 1969.

16. LIONS, J.L. Some Aspects of Modelling Problems in Distributed Parameter Systems, Proceedings IFIP Working Conforonce, Rome, 1976, A.Ruberti, Ed., Lecture Notes in Control and Information Srirnces, Vol.1, Springer-Verlag, Berlin, 1978, 11-41.

17. MURAT, F. Contre-exemples pour divers problemes onle controle intervient dans les cocf-

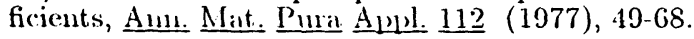

18. MURAT, F. Control in coefficients, Systems ind Control Encyclopedia, M.G.Singh Ed., Perganom Press, 1989, 808-812. 


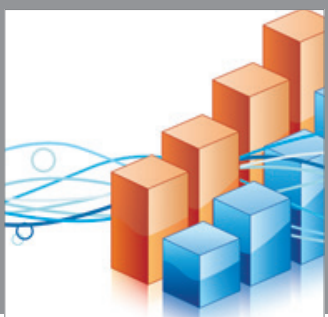

Advances in

Operations Research

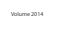

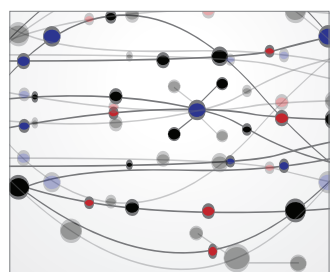

\section{The Scientific} World Journal
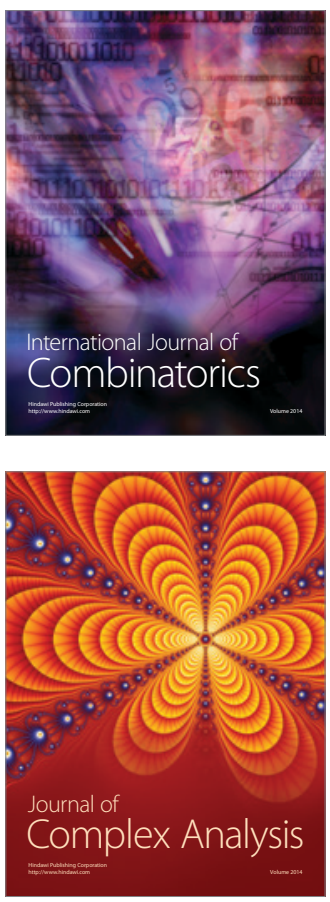

International Journal of

Mathematics and

Mathematical

Sciences
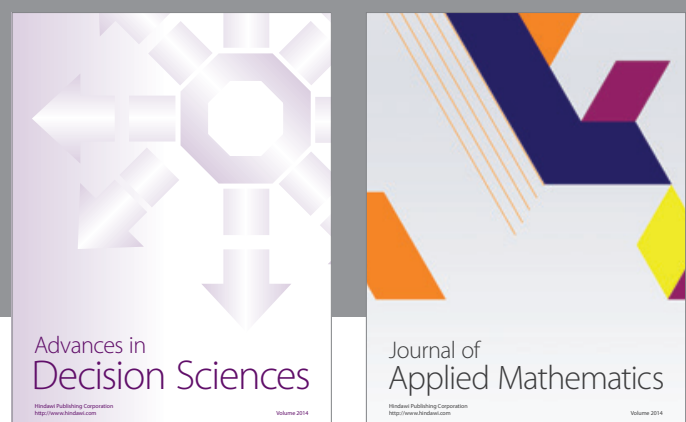

Journal of

Applied Mathematics
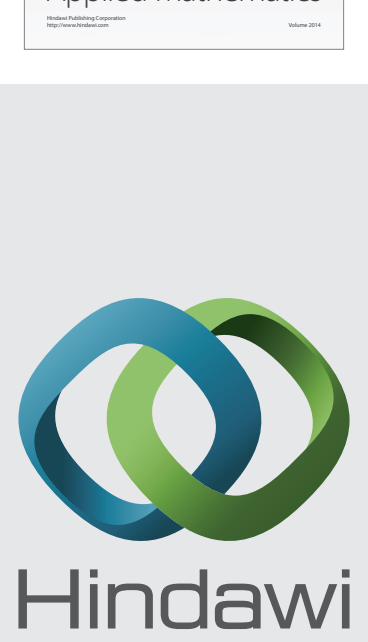

Submit your manuscripts at http://www.hindawi.com
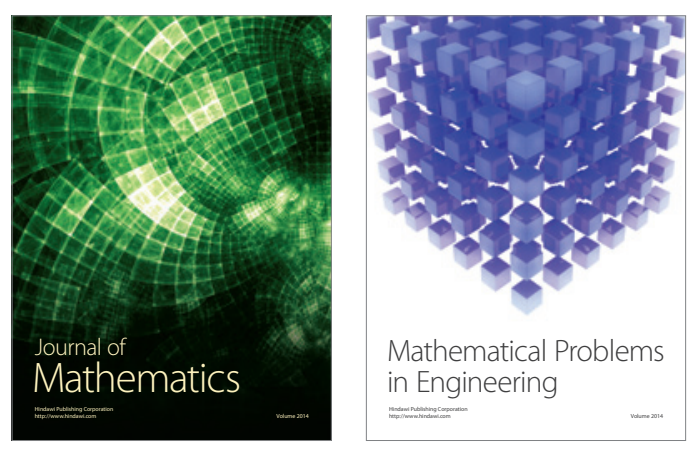

Mathematical Problems in Engineering
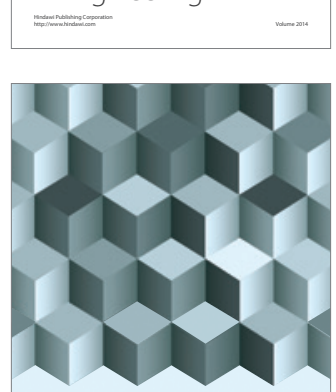

Journal of

Function Spaces
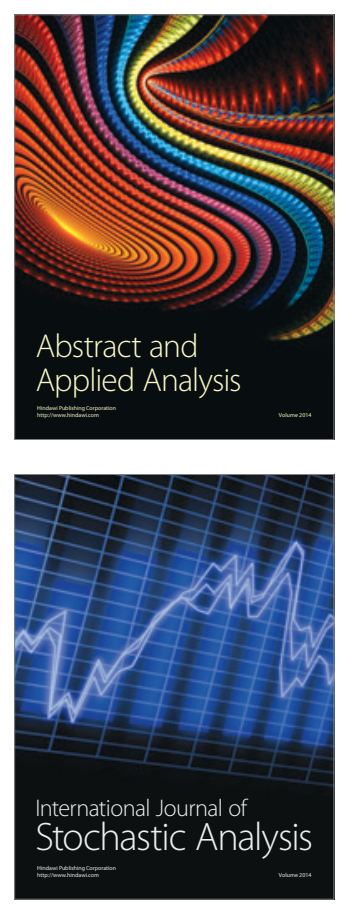

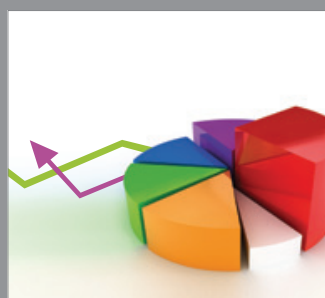

ournal of

Probability and Statistics

Promensencen
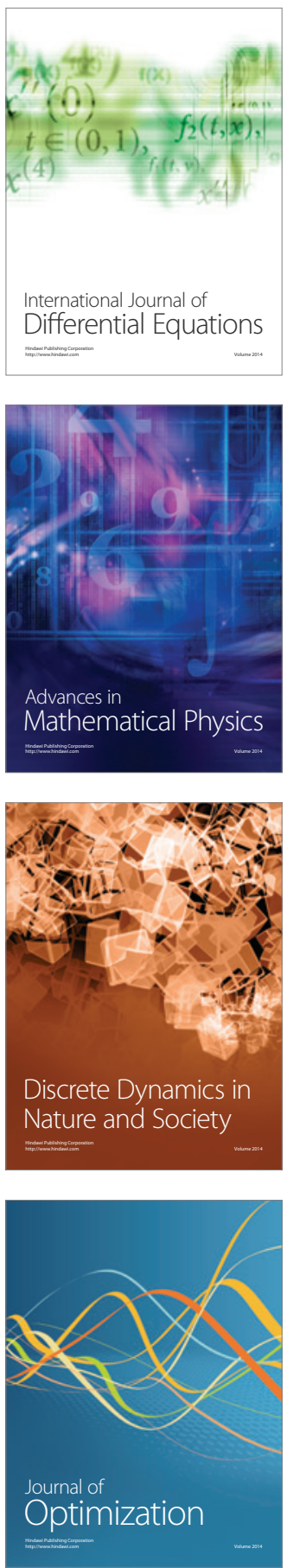